\title{
A RARE FLAVONOID FROM Maydis stigma WITH THE ABILITY TO INFLUENCE LIPID PEROXIDATION IN LIPOSOMES
}

\author{
Z. Maksimovic,* S. Petrovic
}

UDC 547.972

In our previous papers, we reported on the antioxidant effects of the herbal drug Maydis stigma (dried cut stigmata of maize, Zea mays L. ssp. mays, Poaceae) and in the silks of fifteen maize hybrids with economic importance in Serbia [1, 2]. Continuing our research efforts, we have investigated the $\mathrm{MeOH}$ extract of a commercial herbal drug Maydis stigma (Institute for Medicinal Plants Research "Dr. Josif Pancic", Belgrade, Serbia) in an attempt to isolate the compound presumably responsible for the observed in vitro ability to inhibit lipid peroxidation in liposomes (LP). In brief, powdered plant material (1.0 kg) was first defatted with $n$-hexane and $\mathrm{CHCl}_{3}$ in a Soxhlet apparatus, then extracted in the same manner with $\mathrm{MeOH}^{\circ} 50^{\circ} \mathrm{C}$ until exhausted. Dry $\mathrm{MeOH}$ extract (10 g) was fractionated by silicagel VLC using a $\mathrm{CHCl}_{3}$ to $\mathrm{CHCl}_{3}-\mathrm{MeOH}(50: 50$, v/v) gradient at a $10 \%$ rate. The influence of each fraction on LP was determined by the TBA test [3]. Fractions with similar composition (monitored by TLC) and LP inhibitory activity (those eluted with $10 \%$ and $20 \% \mathrm{MeOH}$ in $\mathrm{CHCl}_{3}$, in particular) were pooled together and subjected to polyamide $\mathrm{CC}$ with $70 \%(\mathrm{v} / \mathrm{v})$ aqueous $\mathrm{MeOH}$ as a solvent system. The effluents were combined again based upon the TLC pattern and, finally, subjected to Sephadex LH-20 gel filtration chromatography. The column $(1 \mathrm{~cm}$ internal diameter, $15 \mathrm{~cm}$ length) was eluted sequentially with water and aqueous $\mathrm{MeOH}$ solutions, and compound 1 (27 mg) was isolated.

Compound 1 (bright yellow, amorphous solid). Positive ESI-MS (70 eV), m/z $593[\mathrm{M}+\mathrm{H}]^{+}, 431[\mathrm{M}-(\mathrm{Glc})+\mathrm{H}]^{+}$. PMR (300 MHz, DMSO-d 6 , $\delta$, ppm, J/Hz): 1.05 (1H, d, H-6" $), 1.24$ (1H, br.d, J = 12.3, H-2' $\left.{ }_{\text {eq }}\right), 2.87(1 \mathrm{H}, \mathrm{ddd}, \mathrm{J}=12.3,12.3$,

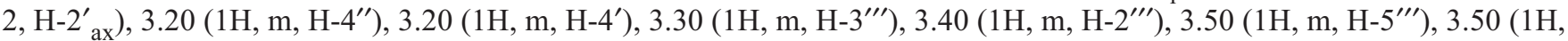
m, H-6"' a), 3.80 (1H, m, H-6"'b), 3.90 (1H, m, H-3"), $3.90\left(1 \mathrm{H}, \mathrm{m}, \mathrm{H}-5^{\prime \prime}\right), 3.97$ (3H, s, OCH $), 4.82\left(1 \mathrm{H}, \mathrm{d}, \mathrm{J}=7.3, \mathrm{H}-1^{\prime \prime}\right)$, $5.30\left(1 \mathrm{H}, \mathrm{dd}, \mathrm{J}=12.3,2, \mathrm{H}-1^{\prime \prime}\right), 6.97$ (1H, s, H-3), 7.00 (1H, dd, H-5'), 7.00 (1H, s, H-8), 7.52 (1H, d, H-2'), 7.58 (1H, dd,

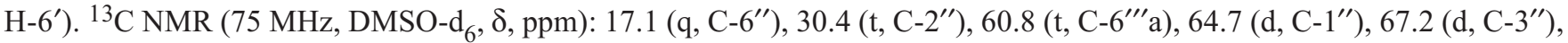

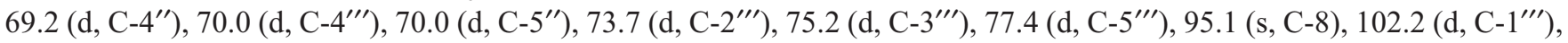
103.5 (d, C-3), 105.1 (s, C-4a), 110.2 (d, C-2'), 113.0 (s, C-6), 115.8 (d, C-5'), 120.4 (d, C-6'), 121.2 (s, C-1'), 148.0 (s, C-3'), 150.9 (s, C-4'), 156.2 (s, C-8a), 157.8 (s, C-5), 163.1 (s, C-7), 164.0 (s, C-2), 182.2 (s, C-4). The spectral data presented are in a good agreement with published data on chrysoeriol 6-C- $\beta$-boivinopyranosyl-7- $O$ - $\beta$-glucopyranoside [4].

\section{ACKNOWLEDGMENT}

This work was supported by Grant No. 143012 of the Ministry of Science and Environmental Protection, Republic of Serbia. The authors also wish to express their profound gratitude to Prof. Dr. Irmgard Merfort, Institut fur Pharmazeutische Wissenschaften, Lehrstuhl fur Pharmazeutische Biologie und Biotechnologie Universitat Freiburg, Germany, who helped in the identification of the isolated compound.

\section{REFERENCES}

1. Z. A. Maksimovic and N. Kovacevic, Fitoterapia, 74, 144 (2003).

2. Z. Maksimovic, D. Malencic, and N. Kovacevic, Bioresource Technol., 96, 873 (2005).

3. Mimica-Dukic, B. Bozin, M. Sokovic, and N. Simin, J. Agric. Food Chem., 52, 2485 (2004).

4. R. Suzuki, Y. Okada, and T. Okuyama, J. Nat. Prod., 66, 564 (2003).

Institute of Pharmacognosy, School of Pharmacy, University of Belgrade, Belgrade, Serbia, e-mail: zmaksim1@pharmacy.bg.ac.rs. Published in Khimiya Prirodnykh Soedinenii, No. 1, p. 98, January-February, 2011. Original article submitted July 29, 2009. 